\title{
Copa do Mundo 2014: um Brasil carioca para gringo ver
}

\author{
2014 World Cup: a carioca Brazil for gringo to see
}

Copa Mundial 2014: un Brasil carioca para gringo ver

André Luiz Leão ${ }^{1}$

Bruno Rafael Ferreira ${ }^{2}$

Thiago Ianatoni Camargo ${ }^{3}$

Bruno Melo Moura ${ }^{4}$

Este artigo foi recebido em 09 de OUTUBRO de 2018 e aprovado em 27 de MAIO de 2019

Resumo: Nos últimos anos, a cidade do Rio de Janeiro tem sido centro de uma série de eventos internacionais, tendo-se tornado a principal sede da Copa do Mundo 2014. Com base nisso, no presente estudo, investigamos como o papel do Rio de Janeiro enquanto cidade-sede da Copa do Mundo de 2014 foi significado por atores sociais da cidade. Para essa finalidade, acessamos as opiniões e os posicionamentos de cidadãos cariocas comuns e os de associações civis locais organizadas para monitorar a realização da Copa do Mundo. Como dados informativos, realizamos entrevistas e levantamos documentos que escrutinamos por meio de uma Análise de Discurso Foucaultiana. A noção foucaultiana de estética da existência serviu, assim, de lente teórica para a interpretação dos resultados que revelaram o entendimento da busca do Rio de Janeiro para inserir-se num contexto cultural e econômico globalizado, sem perder de vista traços que lhe são particulares e entendidos como valorizados mundialmente. Por outro lado, a cidade é vista como representativa do Brasil nessas duas frentes.

Palavras-chave: estética da existência, Análise de Discurso Foucaultiana, Copa do Mundo 2014

Abstract: In recent years, the city of Rio de Janeiro has been the center of a series of international events, having become the headquarters of the 2014 World Cup. Based on this, present study aimed to investigate how the role of Rio de Janeiro as a 2014 World Cup host city was signified by social actors of the city. For this purpose, we accessed opinions and positions of cariocas citizens and civil organizations organized for monitoring the holding of the World Cup. As data were we conducted interviews and collected documents that we scrutinized through Foucauldian Discourse Analysis. Foucault's notion of aesthetics of existence served as a theoretical lens for interpretation of the results, which revealed the understanding of Rio de Janeiro's quest to enter into a globalized cultural and economic context, without losing sight traits that are particular and understood as valued worldwide. On the other hand, the city is seen as representative of Brazil in these two fronts.

Key words: aesthetics of existence, Foucauldian Discourse Analysis, 2014 FIFA World Cup Brazil

Resumen: En los últimos años, la ciudad de Río de Janeiro ha sido el centro de una serie de eventos internacionales, convirtiéndose en la principal sede de la Copa Mundial 2014. Basado en esto, el presente estudio tuvo como objetivo investigar cómo el papel de Río de Janeiro como ciudad anfitriona de la Copa Mundial 2014 fue significado por actores sociales de la ciudad. Para este propósito, accedemos a las opiniones y posicionamientos de ciudadanos cariocas comunes y de asociaciones civiles locales organizadas para monitorear la realización de la Copa del Mundo. Como datos realizamos entrevistas y levantamos documentos que escudriñamos por medio de un Análisis de Discurso de Foucault. La noción de la estética de la existencia de Foucault sirvió como una lente teórica para la interpretación de los resultados, que revelaron al entendimiento de la búsqueda de Río de Janeiro en insertarseen un contexto cultural y económico globalizado, sin perder de vista rasgos que son le particulares y

\footnotetext{
${ }^{1}$ Doutor em Administração pela Universidade Federal de Pernambuco — UFPE, Recife/PE, Brasil. E-mail: aleao21@ hotmail.com.

${ }^{2}$ Doutor em Administração pela Universidade Federal de Pernambuco — UFPE, Recife/PE, Brasil. E-mail: brunortferreira@ gmail.com.

${ }^{3}$ Doutor em Administração pela Universidade Federal de Pernambuco — UFPE, Recife/PE, Brasil. E-mail: ianatoni@gmail.com.

${ }^{4}$ Doutorando em Administração pela Universidade Federal de Pernambuco — UFPE, Recife/PE, Brasil. E-mail: brunomtop@ gmail.com.
} 
entendidos como valorados en todo el mundo. Por otro lado, la ciudad es vista como representante de Brasil en estos dos frentes.

Palabras-Claves: estética de la existencia, Análisis de Discurso de Foucault, Copa Mundial de la FIFA Brasil 2014

\section{Introdução}

Desde a segunda metade da década de 2010, no Brasil, realizou-se um significativo número de eventos internacionais dos mais diversos tipos, com um crescimento de mais de 400\%, entre 2007 e 2016, o que tem contribuído para o crescimento do turismo e da economia nacional (PORTAL BRASIL, 2017). Uma das cidades mais contempladas com tais eventos é o Rio de Janeiro. Ao falarmos especificamente de eventos esportivos, no período indicado a cidade sediou os Jogos Pan-Americanos de 2007 e realizaram-se os Jogos Olímpicos e Paralímpicos de 2016, além de ser escolhida como sede da Copa das Confederações de 2013 e da Copa do Mundo de 2014.

Mais do que apenas uma entre 12 cidades-sede, Rio de Janeiro foi escolhida pela Fédération Internationale de Football Association (FIFA) como abrigo do International Broadcast Center (IBC) da Copa do Mundo de 2014 (GOVERNO DO RIO DE JANEIRO, 2011) e o Maracanã foi o principal palco da Copa das Confederações de 2013 e da Copa do Mundo de 2014, com o privilégio de sediar a partida final do torneio, além de outros seis jogos, totalizando o maior número de partidas do mundial. Além disso, a cidade foi líder nacional, durante a Copa, da ocupação de leitos de hotéis, alcançando um índice de 98\% (REVISTA EXAME, 2014; MENDONÇA, 2014).

Vale lembrar que o turismo é uma atividade que favorece o desenvolvimento local; além de gerar renda direta e indireta, é capaz de preservar ou dissipar a identidade e a cultura local via padrões de consumo ali executados. Seu impacto - positivo ou negativo - depende da maneira com que os atores sociais se organizam e interagem para alcançar objetivos comuns de melhoria na qualidade de vida, maior competitividade e poder de atração turística, bem como a preservação e a proteção cultural (CUNHA; CUNHA, 2005; SOUZA; GIL, 2015).

Mas o que teria levado o Rio de Janeiro a ocupar essa importância central no evento? Afinal de contas é Brasília a capital do País e São Paulo a cidade economicamente mais desenvolvida. A relevância dada à cidade pode ser um reflexo do papel histórico, econômico e cultural para o País, sobretudo por ter sido capital do Brasil desde a época colonial até 1960, quando da inauguração de Brasília. Por outro lado, trata-se da paisagem brasileira mais reconhecida internacionalmente, vide o exclusivo título, conferido pela United Nations Education Scientific and Cultural Organization (Unesco), de patrimônio mundial na categoria Paisagem Cultural Urbana (PORTAL BRASIL, 2012). 
A despeito das inúmeras polêmicas referentes às escolhas das cidades-sede e dos gastos públicos realizados para viabilizar o evento, o caso da capital fluminense parece particular de como ela tenha sido utilizada como um símbolo do próprio evento perante o mundo e o próprio País. Diante desse contexto, a população carioca apresenta opiniões favoráveis e desfavoráveis sobre o evento e o papel do Rio de Janeiro na realização. Com base nisso, no presente estudo, investigamos a seguinte questão: como o papel do Rio de Janeiro enquanto cidade-sede da Copa do Mundo de 2014 foi significado por atores sociais da cidade?

Para cumprir o objetivo traçado, acessamos as opiniões e os posicionamentos de cidadãos cariocas comuns e de associações civis locais organizadas para monitorar a realização da Copa do Mundo. Para tal, alinhamos a proposição apresentada ao campo de estudos da Consumer Culture Theory (CCT), assumindo tais atores da sociedade carioca como consumidores do evento.

$\mathrm{Na}$ abordagem adotada, evidenciamos implicações para o turismo. Um exemplo é a pesquisa de Dermody e outros (2003), na qual avaliam como a repercussão sociocultural de sediar um grande evento esportivo enriquece as possibilidades turísticas da cidade. Em outro estudo relevante, Bryce e outros (2013) apreciam como os saberes estabelecidos no cotidiano tornam os países do Oriente Médio mais fascinantes para o turismo. Em tais trabalhos, assumimos a realidade como campo de relações de poder em que narrativas são constituídas de forma histórica e contingente (ARNOULD; THOMPSON, 2015), produzindo as formas com as quais se podem entender e significar determinados locais, tornando-os atrativos turísticos para as escolhas dos consumidores (BRYCE et al., 2013; HANNA, 2013; PERFETTO; DHOLAKIA, 2010; VOASE, 2007).

Ao analisarmos os discursos dos consumidores sobre como avaliaram o papel da cidade do Rio de Janeiro em relação ao evento, evidenciamos uma estilização dessa percepção, o que nos levou à identificação — consistentemente com a abordagem teórico-metodológica adotada, como se verá — da noção foucaultiana de estética da existência como uma lente teórica para a interpretação dos dados.

\section{Fundamentação teórica}

Pesquisas em CCT investigam o consumo a partir de sua agência social. Esse entendimento tem sido consolidado por meio de correntes teóricas e epistemológicas em que se entende a realidade como narrativas constituídas em meio a relações de poderes estabelecidas em condições históricas e contextualizadas. Entre essas correntes, destaca-se a teoria foucaultinana (ARNOULD; THOMPSON, 2015). 
Nesse sentido, tais narrativas podem ser compreendidas com base na noção de Foucault sobre o discurso, como um conjunto de conhecimentos que definem aquilo que pode ser dado por verdadeiro ou falso (FOUCAULT, 2014a). Assim, em uma sociedade, o que se entende como verdade parte de um jogo em meio a um regime de verdade, ou seja, entre diferentes saberes conhecidos e vinculados a certos domínios, como os conhecimentos científico, religioso, técnico, legal e a sabedoria popular. Alguns encontram condições mais propícias, que os legitimam e definem-nos como verdades (FOUCAULT, 2016). Por sua vez, essas verdades organizam, conduzem e regulam um conjunto heterogêneo de elementos sociais, como instituições, leis, grupos coletivos, campos de conhecimento (FOUCAULT, 1988). Esses conjuntos são definidos pelo filósofo francês como dispositivos, que do mesmo modo como são regulados pelos discursos verdadeiros, também sustentam o estatuto de verdade (FOUCAULT, 2014b). O modo de as práticas discursivas e as não discursivas relacionarem-se e estabelecerem uma forma de separar, classificar e organizar o modo como a realidade, as coisas e as pessoas são entendidas, evidencia relações de poderes que exercem um modo de governo sobre os indivíduos, uma forma de produzir condutas e subjetividades (FOUCAULT, 2014b; 2010a).

Pesquisas em CCT orientadas por essa noção ajudam a investigar como as práticas de marketing, da mídia, das ciências e do próprio mercado produzem saberes que, assumidos como verdadeiros, incidem sobre práticas e experiências, regulando-as conforme uma lógica de consumo, bem como delineiam como devem ser seus consumidores (CANNIFORD; KARABABA, 2013; HANNA, 2013). Nesse sentido, Canniford e Karababa (2013), ao analisarem as mudanças na prática do surfe no Havaí, evidenciaram como instituições de turismo, órgãos de segurança, praticantes do esporte produziram verdades sobre o esporte, mantendo sua prática no estado americano entendida como rústica, apesar de toda a atualização pela tecnologia, sustentando o esporte como uma prática libertária e, com isso, promovendo a prática local como uma experiência atrativa aos consumidores.

De modo semelhante, a noção de governo, que, como mencionado, se refere à condução de práticas (FOUCAULT, 2014b), parte de como essas verdades orientam instituições e práticas sociais, regulando o mercado e os consumidores. Isso se verifca, por exemplo, em trabalhos em que se investigam formas de regulação de alimentos (JOHNSON et al., 2017; YNGFALK, 2016) ou como a tecnologia tem orientado o consumo de mídia e serviços (ZJAC, 2015; COLL, 2013; BECKETT, 2012; ZWICK; DENEGRI-KNOTT, 2009), ao examinarmos como as verdades acerca desses objetos têm orientado os concumidores a aceitarem, procurarem ou defenderem o interesse e o consumo de certos tipos de produtos e serviços do mesmo modo como tais recursos servem como forma de cerceamento 
da condução desses consumidores, moldando suas formas de ser (JOHNSON et al., 2017; YNGFALK, 2016; ZWICK; DENEGRI-KNOTT, 2009).

Assim, verdade e governo compreendem formas de subjetivação dos indivíduos; contudo Foucault não limita a subjetividade à objetivação das pessoas. Há, nessas relações, um espaço de agência para os indivíduos, no qual eles podem exercer o governo de si sobre si mesmo. Tal espaço de ação é apresentado por Foucault como uma possibilidade de liberdade do ser que não compreende uma autonomia de ação, mas uma possibilidade para aceitar ou resistir às condições possíveis pela relação de verdade e governo em que ele se insere; logo, essa liberdade compreende um espaço na experiência do indivíduo de governar a si mesmo (MIKKONEN et al., 2011; GOULDING; SAREN, 2009). Esse entendimento emerge, na teoria foucaultiana, da noção de governo de si, que compreende como os indivíduos governam a si mesmos por meio de técnicas e práticas que refletem uma verdade (FOUCAULT, 2010c), mas também resistem de algum modo a elas, de forma a atender a seus interesses e desejos (FOUCAULT, 2016). Essa resistência, portanto, não se refere a uma negação, mas a uma negociação: uma forma de transformar e singularizar seu modo de ser (FOUCAULT, 1984; 2010c). Essa forma singular do ser, em parte reflexividade de uma verdade, em parte governo de interesses próprios, compreende o que Foucault denomina de uma forma ética de ser (FOUCAULT, 2016). Por sua vez, essa forma ética revela uma estética que deve servir de referência para si e para outros de uma obra de arte: uma arte de si descrita por Foucault como uma estética da existência (FOUCAULT, 1984).

Vale lembrar que a estética da existência expressa um modo de subjetivação em que o indivíduo conduz a si por si mesmo, tanto se reconhecendo como sujeito, como sendo reconhecido por uma alteridade social como tal (FOUCAULT, 1984a; 2010d). Com isso, a estética da existência, como modo de subjetivação, apresenta-se como uma forma que serve de modelo ou referência para si e para outros como uma forma de vida bela (GOULDING; SAREN, 2009; WEISKOPF, 2002).

Embora pouco explorada em pesquisas no campo, a noção de estética da existência aparece em trabalhos que investigam, a partir de experiências dos indivíduos, a constituição de suas subjetividades em arranjos sociais (GOULDING; SAREN, 2009; WEISKOPF, 2002). Em seu ensaio sobre arranjos organizacionais, Weiskopf (2002) reflete sobre como as tensões entre as diferentes subjetividades podem evidenciar uma produção estético-moral de posições de sujeito. Por sua vez, Goulding e Saren (2009) investigam como as práticas de consumidores de narrativas fantásticas, em encontros de grupos, revelam formas éticas e estéticas que evidenciam diferentes orientações de gênero. Semelhantemente, as posições e verdades reveladas pelos discursos dos consumidores sobre a Copa do Mundo de 2014 
podem revelar como a imagem do jeito carioca de ser compreende uma estética da existência do brasileiro para si e para o mundo.

\section{Procedimentos metodológicos}

Para a realização da pesquisa, foi adotada a Análise de Discurso Foucaltiana (ADF), cujo objetivo compreende a apreensão das condições que permitem que certos saberes se estabeleçam como verdades. Para tal, o método visa ao desvelamento de formações discursivas (FOUCAULT, 2014). Essas formações abrangem um conjunto de enunciados utilizados em certas funções e sob o domínio de regras distintas, de forma a manifestar as relações que revelam saberes. Com base nessa definição, as categorias analíticas da ADF são apresentadas (Quadro 1).

\section{Quadro 1. Descrição das categorias analíticas}

\begin{tabular}{|l|l|}
\hline Categoria & \multicolumn{1}{c|}{ Definição } \\
\hline Enunciados & $\begin{array}{l}\text { São funções de existência estabelecidas no interior dos signos. Não devem ser entendidos } \\
\text { como estrutura ou mesmo unidades, mas como funções que atravessam a estrutura da } \\
\text { linguagem e os domínios de saberes, revelando temas contingentes a um tempo e lugar. } \\
\text { Decorre disso a importância em mencionar-se que os enunciados não são evidenciados em } \\
\text { signos específicos ou em uma reunião deles, nem tampouco de modo isolado, uma vez que } \\
\text { é de esperar-se que existam relações entre eles. }\end{array}$ \\
\hline $\begin{array}{l}\text { Funções } \\
\text { enunciativas }\end{array}$ & $\begin{array}{l}\text { Diz respeito à maneira como os enunciados revelam ações, uma vez que são evidenciados } \\
\text { em práticas discursivas, que indicam como o discurso existe para determinados fins. Essas } \\
\text { funções não são encontradas no nível superficial da linguagem, operadas por um sujeito, mas } \\
\text { em diferentes vozes, revelando espaços de diferenciação do discurso e evidenciando } \\
\text { diferentes posiçôes de subjetivação. Do mesmo modo, mostram como os enunciados, ao } \\
\text { coexistirem em um tecido composto por tantos outros, demonstram uma materialidade que } \\
\text { lhes permite diferentes formas de utilização. }\end{array}$ \\
\hline $\begin{array}{l}\text { Regras de } \\
\text { formação }\end{array}$ & $\begin{array}{l}\text { As formações discursivas são evidenciadas por estabelecerem-se em meio a certas regras, } \\
\text { que revelam uma noção de existência, coexistência, manutenção, modificação e } \\
\text { desaparecimento de sentido em um dado campo de conhecimento. }\end{array}$ \\
\hline $\begin{array}{l}\text { Formações } \\
\text { discursivas }\end{array}$ & $\begin{array}{l}\text { Trata-se de um conjunto, com certa regularidade, que sustenta a constituição de sentidos que } \\
\text { permitem o estabelecimento de um saber e é revelado pelo agrupamento de enunciados } \\
\text { interligados e suas relações com funções enunciativas, em certas regras de formação. }\end{array}$ \\
\hline
\end{tabular}
Fonte: Foucault (2014).

Com base nesses conceitos, a análise foi operacionalizada na proposta de Souza-Leão (SOUZALEÃO; COSTA, 2018; SOUZA-LEÃO; MOURA, 2018; LEÃO et al., 2017). Primeiramente, identificamos os enunciados e suas relações, as quais podem apresentar-se de duas formas: as primeiras, síncronas, acenam para enunciados que se explicam mutuamente; as segundas, incidentes, aludem a enunciados que explicam outros. Com base nisso, passamos à observação do uso desses enunciados, de modo a identificarmos suas funções enunciativas. Vale dizer que uma função pode estar vinculada a diferentes enunciados, bem como ao contrário. Na sequência, partimos do entendimento dessas relações 
em busca da identificação das regras de formação. Tanto essas regras, como o modo como elas se estendem aos enunciados e funções direcionam a determinação das formações discursivas.

Foucault (2014a) utiliza o termo arquivo para descrever o conjunto de dados reunidos para análise que devem ser coletados de maneira a reunir certo número de práticas discursivas, por meio das quais é possível identificarmos enunciados. O arquivo da pesquisa foi formado por práticas discursivas de dois grupos: cidadãos comuns e associações organizadas com o objetivo de monitorar a organização da Copa do Mundo, em ambos os casos quanto aos seus posicionamentos sobre o Rio de Janeiro como cidade-sede.

Foram coletados dados primários e secundários. Os secundários abrangem documentos levantados em diferentes meios eletrônicos da Internet, que podem ser divididos em dois grupos: sites e blogs gerenciados por grandes grupos de mídia e portais mais acessados no País, em que levantamos matérias com trechos da expressão de opiniões dos dois grupos investigados, sites de agentes relacionados com a organização da Copa do Mundo no País e os mantidos por produtores independentes e por organizações civis, considerados importantes por leitores que comentam e compartilham os conteúdos. Ao todo, 223 documentos, publicados entre setembro de 2010 e junho de 2015, foram reunidos.

Para a coleta dos dados primários, realizamos 19 entrevistas etnográficas — técnica que permite a abordagem de questões específicas em ambientes naturais (FLICK, 2009) —, com moradores da cidade, selecionados aleatoriamente e abordados em áreas públicas no centro do Rio de Janeiro. Esses contatos foram registrados em áudio - incluindo-se a averbação de autorização da gravação por parte dos participantes e o entendimento de que as identidades seriam preservadas. Todos os dados (primários e secundários) foram organizados e analisados com suporte de um software de pesquisa qualitativa.

Além dos procedimentos de coleta e análise de dados propriamente ditos, adotamos critérios de qualidade da pesquisa qualitativa (vide PAIVA; LEÃO; MELLO, 2011): a análise dos dados foi realizada e comparada por diferentes pesquisadores, num processo de triangulação; durante o trabalho, adotamos uma condução cautelosa, considerando-se constantes reinterpretações dos dados, sobretudo diante da teoria adotada, o que evidencia a reflexibilidade dos pesquisadores no processo; a construção do arquivo, por sua vez, compreende um terceiro critério, uma vez que se procura atender à noção de representatividade do corpus em relação ao objeto investigado; por fim, busca-se apresentar os resultados de forma rica e detalhada.

Por fim, vale destacar a escolha pela escrita em primeira pessoa do plural. Antes de um recurso estilístico, trata-se de um alinhamento epistemológico, axiológico e retórico à abordagem paradigmática 
COPA DO MUNDO 2014: UM BRASIL CARIOCA

PARA GRINGO VER
André Luiz Maranhão de Souza Leão Bruno Rafael Torres Ferreira Thiago Ianatoni Camargo Bruno Melo Moura

de pesquisa adotada, uma vez que os pesquisadores são entendidos como parte integrante da produção de conhecimento do objeto investigado, assim como todos os participantes da pesquisa (i.e., entrevistados e produtores dos textos analisados) (LINCOLN; LYNHAM; GUBA, 2018).

\section{Descrição dos resultados}

Os achados nos levaram à identificação de uma formação discursiva, constituída com base em duas regras, cinco funções e 11 enunciados. Na Figura 1, apresentam-se tais categorias e as relações estabelecidas entre elas e os enunciados. As primeiras são apresentadas por meio de setas, uma vez que uma categoria leva à inferência da próxima. Quanto às relações entre enunciados, foram utilizadas linhas para as síncronas e as setas para os incidentes, de forma fidedígna ao que tais relações elucidam.

A formação evoca a busca do Rio de Janeiro para inserir-se num contexto cultural e econômico globalizado, sem perder de vista traços que lhe são particulares e entendidos como valorizados mundialmente. Isso revela a presença de saberes particulares que dá suporte a um dado discurso, alinhado ao que se adota como verdadeiro sobre o que é ser carioca. Dessa maneira, a cidade é vista como representativa do Brasil nessas duas frentes: aquela que é capaz de inserir o País num cenário global e de simbolizar a brasilidade perante o mundo, de tal modo que uma subjetividade configurada como brasileira se mostre análoga ao jeito carioca de ser. Por conta disso, denominamos tal formação discursiva de "um Brasil carioca para gringo ver".

As duas vertentes aqui apresentadas para descrever a formação discursiva ancoram-se nas duas regras de formação eliciadas. À primeira delas denominamos de adequação global, uma vez que reflete como a cultura ocidental globalizada pelas economias desenvolvidas se impõe como padrão ideológico, de cunho estético e ético, perseguido pelo Rio de Janeiro e, por extensão, pelo Brasil. À segunda denominamos de particular exótico, pois trata de como o carioca percebe a si e sua cidade - e, por extensão, o brasileiro e o País - como distintos de forma sui generis do ponto de vista da cultura ocidental globalizada. Para denominar essas regras, adotamos locuções substantivas, uma vez que elas se referem a noções basilares das formações discursivas. 
Figura 1. Mapa da formação discursiva

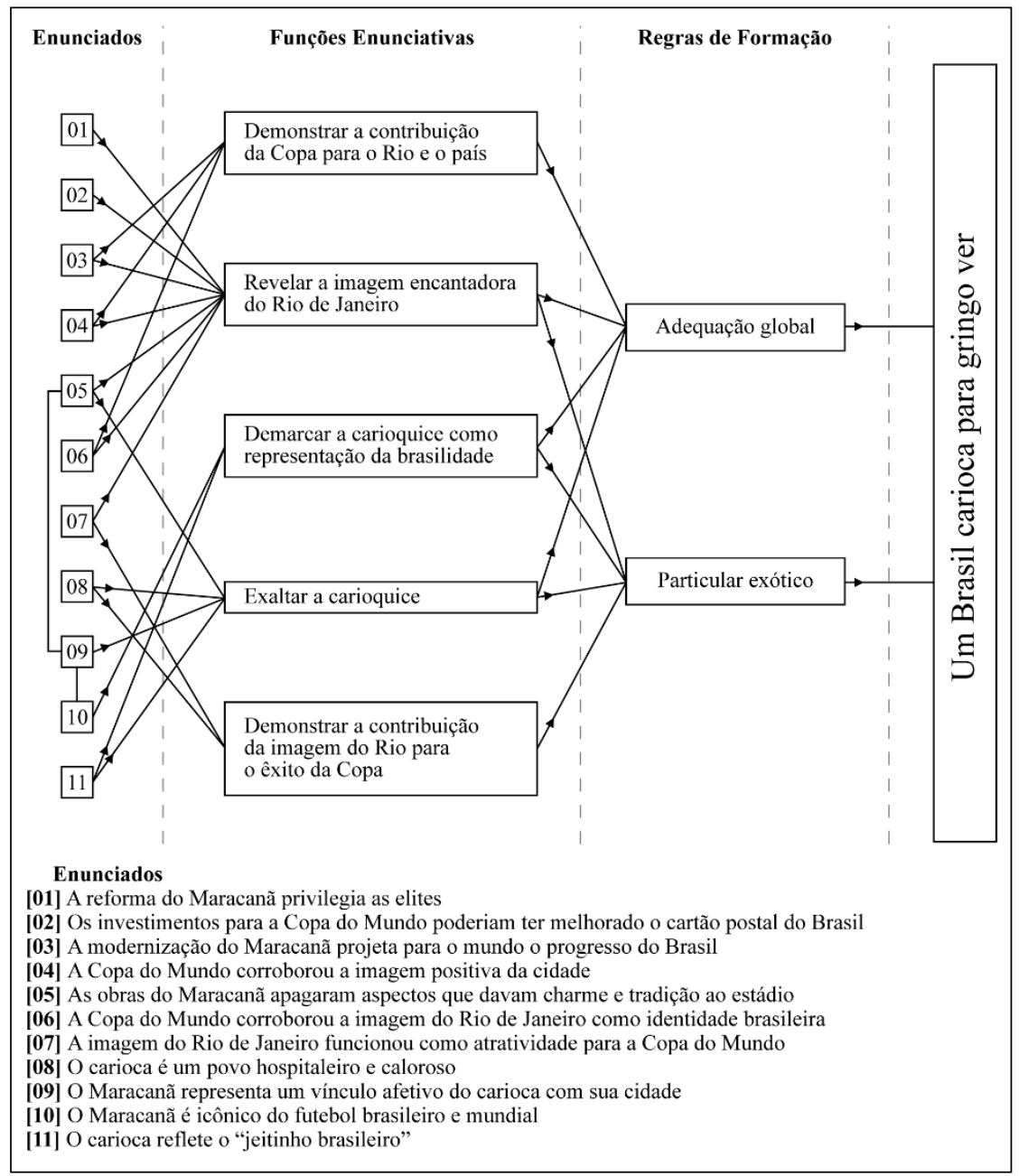

Fonte: Elaboração dos autores.

Apresentamos os enunciados, por sua vez, na forma de proposições afirmativas, com o intuito de dar clareza à sua significação e aos contextos em que aparecem nos dados. No Quadro 2, mostra-se uma descrição de cada enunciado e a forma como foram identificados nos dados.

\section{Quadro 2. Descrição dos enunciados}

\begin{tabular}{|c|l|l|}
\hline Cód. & Enunciado & \multicolumn{1}{c|}{ Descrição } \\
\hline 01 & $\begin{array}{l}\text { A reforma do Maracanã } \\
\text { privilegia as elites }\end{array}$ & $\begin{array}{l}\text { Afirma que o acesso a uma arena de padrão internacional é limitado a um } \\
\text { grupo seleto da população carioca. Isso é evidenciado por meio de } \\
\text { reclamações relativas aos altos preços de ingressos, produtos e serviços } \\
\text { ofertados no estádio. }\end{array}$ \\
\hline 02 & $\begin{array}{l}\text { Os investimentos para a } \\
\text { Copa do Mundo }\end{array}$ & $\begin{array}{l}\text { Refere-se à perda de oportunidades para reformar importantes aparelhos } \\
\text { turísticos da cidade, que servem de referência do Brasil no exterior. Isso é }\end{array}$ \\
\hline
\end{tabular}




\begin{tabular}{|c|c|c|}
\hline & $\begin{array}{l}\text { poderiam ter melhorado } \\
\text { o cartão-postal do Brasil }\end{array}$ & $\begin{array}{l}\text { evidenciado em argumentos que demonstram como a Copa do Mundo } \\
\text { poderia ter sido utilizada para a melhoria da cidade como destino turístico. }\end{array}$ \\
\hline 03 & $\begin{array}{l}\text { A modernização do } \\
\text { Maracanã projeta para o } \\
\text { mundo o progresso do } \\
\text { Brasil }\end{array}$ & $\begin{array}{l}\text { Diz respeito a como o novo Maracanã, ao adequar-se ao padrão mundial de } \\
\text { arenas, evidencia o desenvolvimento brasileiro. Tal aspecto é identificado } \\
\text { em relatos sobre a inserção do País na lógica global de fruição do espetáculo } \\
\text { futebolístico, com implicações na mudança comportamental dos torcedores. }\end{array}$ \\
\hline 04 & $\begin{array}{l}\text { A Copa do Mundo } \\
\text { corroborou a imagem } \\
\text { positiva da cidade }\end{array}$ & $\begin{array}{l}\text { Aborda o modo como a realização do evento projetou globalmente as } \\
\text { qualidades naturais, humanas e culturais do Rio de Janeiro. Tal aspecto foi } \\
\text { identificado em relatos que demonstram como o evento reforçou a imagem } \\
\text { positiva que a cidade apresenta mundialmente. }\end{array}$ \\
\hline 05 & $\begin{array}{l}\text { As obras do Maracanã } \\
\text { apagaram aspectos que } \\
\text { davam charme e } \\
\text { tradição ao estádio }\end{array}$ & $\begin{array}{l}\text { Refere-se ao entendimento de que a reforma da arena, decorrente de sua } \\
\text { adequação à Copa, extinguiu características que remetiam à memória afetiva } \\
\text { dos cariocas. Isso se evidencia em relatos que mencionam a mudança na } \\
\text { forma de assistir aos jogos e a experiência social e estética do estádio. }\end{array}$ \\
\hline 06 & $\begin{array}{l}\text { A Copa do Mundo } \\
\text { corroborou a imagem do } \\
\text { Rio de Janeiro como } \\
\text { identidade brasileira }\end{array}$ & $\begin{array}{l}\text { Apresenta a Copa do Mundo como meio para promover a identidade } \\
\text { brasileira, por meio de características culturais e humanas próprias do Rio } \\
\text { de Janeiro e seu reconhecimento mundial. Isso é evidenciado na maneira } \\
\text { como comportamentos do carioca e eventos paralelos ao mundial, com } \\
\text { artistas cariocas, são significados como representativos da cultura e do estilo } \\
\text { de vida brasileiros. }\end{array}$ \\
\hline 07 & $\begin{array}{l}\text { A imagem do Rio de } \\
\text { Janeiro funcionou como } \\
\text { atratividade para a Copa } \\
\text { do Mundo }\end{array}$ & $\begin{array}{l}\text { Aponta como a imagem positiva que a cidade apresenta mundialmente foi } \\
\text { utilizada para promover a Copa do Mundo. Isso é evidenciado em } \\
\text { argumentos que remetem a como as características naturais, humanas e } \\
\text { culturais da cidade têm reconhecimento mundial. }\end{array}$ \\
\hline 08 & $\begin{array}{l}\text { O carioca é um povo } \\
\text { hospitaleiro e caloroso }\end{array}$ & $\begin{array}{l}\text { Compreende a percepção de que o povo do Rio de Janeiro recebe bem } \\
\text { aqueles que visitam a cidade. Tal aspecto é evidenciado em afirmações de } \\
\text { que os turistas se sentem bem pela receptividade, em diferentes situações, } \\
\text { de suas experiências nesse destino. }\end{array}$ \\
\hline 09 & $\begin{array}{l}\text { O Maracanã representa } \\
\text { um vínculo afetivo do } \\
\text { carioca com sua cidade }\end{array}$ & $\begin{array}{l}\text { Evoca como o estádio simboliza a relação emocional do carioca com sua } \\
\text { cidade. Isso é demonstrado pelo relato de momentos marcantes, para a vida } \\
\text { da cidade e do País, ocorridos no Maracanã. }\end{array}$ \\
\hline 10 & $\begin{array}{l}\text { O Maracanã é icônico } \\
\text { do futebol brasileiro e } \\
\text { mundial }\end{array}$ & $\begin{array}{l}\text { Refere-se ao entendimento de que o Maracanã é o maior símbolo do futebol } \\
\text { brasileiro, tanto para o País, quanto para o mundo. Tal ponto é revelado por } \\
\text { narrativas que rememoram o estádio como importante palco da história do } \\
\text { futebol brasileiro e do mundial, tanto em relação a competições de clubes, } \\
\text { como de seleções. }\end{array}$ \\
\hline 11 & $\begin{array}{l}\text { O carioca reflete o } \\
\text { "jeitinho brasileiro" }\end{array}$ & $\begin{array}{l}\text { Revela como o carioca, e por extensão o brasileiro, encontra soluções para } \\
\text { dificuldades. Isso é evidenciado em situações em que pessoas relatam como } \\
\text { desenvolveram saídas paliativas para adversidades ocorridas em } \\
\text { decorrência da organização e realização do evento. }\end{array}$ \\
\hline
\end{tabular}

Fonte: Elaboração dos autores.

No Quadro 3, apresentamos as funções enunciativas. Por se tratar de ações, elas são representadas por orações iniciadas por verbos no infinitivo.

\section{Quadro 3. Descrição das funções enunciativas}

Demonstrar a contribuição da Copa para o Rio e o País
Apresenta as benfeitorias da Copa do Mundo para a cidade e, por extensão, para o Brasil. Tais aspectos se relacionam com a 


\begin{tabular}{|l|l|}
\hline & $\begin{array}{l}\text { infraestrutura física, a vida social e a uma projeção de } \\
\text { desenvolvimento. }\end{array}$ \\
\hline $\begin{array}{l}\text { Demonstrar a contribuição da } \\
\text { imagem do Rio para o êxito da Copa }\end{array}$ & $\begin{array}{l}\text { Evidencia o modo como a imagem positiva da cidade e de sua } \\
\text { população funcionou como atrativo para aqueles que usufruíram da } \\
\text { Copa do Mundo. }\end{array}$ \\
\hline $\begin{array}{l}\text { Revelar a imagem encantadora do } \\
\text { Rio de Janeiro }\end{array}$ & $\begin{array}{l}\text { Indica o entendimento de que o Rio de Janeiro é percebido } \\
\text { globalmente como um cenário natural, humano e cultural de charme e } \\
\text { inspiração. A Copa do Mundo teria tanto beneficiado essa imagem, } \\
\text { como se beneficiado dela, e a descaracterizado em alguns aspectos. }\end{array}$ \\
\hline Exaltar a carioquice & $\begin{array}{l}\text { Destaca traços que definem o que é ser carioca marcados por um estilo } \\
\text { de vida que preza laços sociais, territoriais e afetivos e seu engenho. A } \\
\text { Copa do Mundo serviu como um ponto de visibilidade desse aspecto. }\end{array}$ \\
\hline $\begin{array}{l}\text { Demarcar a carioquice como } \\
\text { representação da brasilidade }\end{array}$ & $\begin{array}{l}\text { Generaliza os traços que definem o que é ser carioca como } \\
\text { característica da cultura e do estilo de vida do brasileiro de forma geral. } \\
\text { Tal fenômeno foi amplificado em virtude da visibilidade propiciada } \\
\text { pela Copa do Mundo. }\end{array}$ \\
\hline
\end{tabular}

Fonte: Elaboração dos autores.

Para elucidar a análise, ilustramos exemplos elucidativos das relações apresentadas na Figura 1, de modo a demonstrar feixes de relações referentes às duas regras de formação e a todas as funções enunciativas, cobrindo o máximo de enunciados possível.

Num primeiro exemplo, um depoimento do geógrafo Christopher Gaffney, veiculado em matéria do site de jornalismo independente publica:

O Maracanã é um sítio de conflito nas representações agora. Acho que o governo quer representar o Brasil para o mundo afora como um país "civilizado". Então tem que ter a torcida comportada, tem que ter cadeira cativa, tem que ter camarote, ar condicionado, sala VIP... Estamos pagando pelo estádio três, quatro vezes e, por isso, vamos ter que pagar ingressos mais caros, e também a manutenção é a mais cara no estádio. O povo está sendo abusado nesse sentido, está sendo afastado de seu lugar popular e proibido de participar de sua cultura futebolística.

Na primeira parte de sua fala, ao apontar que o investimento feito para a reforma do Maracanã serve a uma tática política para projetar a imagem de País desenvolvido, tanto econômico, como culturalmente, evidenciamos o enunciado de que a modernização do Maracanã projeta para o mundo o progresso do Brasil. Na sequência, a argumentação explicita como essa reforma reconfigurou o espaço de fruição do espetáculo futebolístico, tendo como consequência tanto a elevação dos preços para o carioca frequentar a nova arena, quanto a concepção de uma nova forma de assistir-se aos jogos. Nesse aspecto, identificamos uma acusação explícita de que a reforma no Maracanã privilegia as elites. Tal argumento é complementado no fechamento de sua fala, quando o geógrafo denuncia um processo de 
marginalização do carioca médio, agora afastado do estádio que era palco de uma manifestação popular da cidade, remetendo ao entendimento de que o Maracanã representa um vínculo afetivo do carioca com a cidade. Além desses aspectos, a crítica à nova configuração arquitetônica da arena revela, implicitamente, o entendimento de que as obras do Maracanã apagaram aspectos que davam charme e tradição ao estádio.

O depoimento aqui apresentado tem como função primordial exaltar a carioquice, o que fica evidente nos enunciados que remetem ao Maracanã como exemplo de vínculo do carioca com a cidade e do caráter tradicionalista referente ao estádio pré-reforma. Por outro lado, outra função evidenciada é

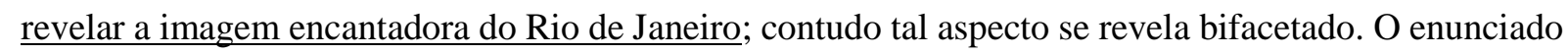
em que se reclama a perda de identidade da nova arena remete a um encanto saudosista. Nesses aspectos revela-se a compreensão de um Rio de Janeiro particular.

Para ilustrar a segunda regra de formação, alguns trechos de entrevistas com transeuntes, realizadas no centro da cidade do Rio de Janeiro:

\section{Entrevistado \#2:}

[...] eu acho que foi perfeita a escolha do Rio de Janeiro, o Rio é uma cidade linda, o povo é muito hospitaleiro, eu acho que isso foi uma lição que a gente deu para o mundo inteiro, eu acho que foi fantástico [...] ficou a imagem boa de que somos muito hospitaleiros, somos um povo muito simpático, recebemos muito bem os turistas [...]

\section{Entrevistado \#15}

(após referir-se à violência como um dos principais pontos que marcaram a Copa no Brasil, o entrevistado argumenta, em contrapartida:)

[...] mas eu acho que do pessoal do Rio em si não ficou uma imagem muito ruim não porque o carioca em si é bem receptivo, ele é bem desenvolto, nessa questão de conversar... ele é bem... qual é a palavra mesmo?... Acolhedor!

Nos dois trechos, os entrevistados em questão evocam, de forma positiva, os aspectos naturais e humanos da cidade. Tais aspectos revelam o entendimento de que o carioca é um povo hospitaleiro e caloroso e que a imagem do Rio de Janeiro funcionou como atratividade para a Copa do Mundo. Esses dois enunciados mencionados relacionam-se de modo incidental: o sentido de caracterização do carioca, expresso pelo primeiro enunciado, apresenta-se como base para o sentido do enunciado referente à imagem da cidade. Tal caracterização do carioca funciona como uma forma de exaltar-se a carioquice e um sentido de revelar a imagem encantadora do Rio de Janeiro, função corroborada pelo argumento de que a imagem da cidade tenha sido atrativa para o evento. Por outro lado, esse retrato reforça a concepção de uma identidade brasileira por meio de características relacionadas com o Rio de Janeiro, sustentando uma demarcação da carioquice como representação da brasilidade. Tais aspectos assumem uma dupla posição de tanto evidenciar uma particularização do Rio de Janeiro, como seu alinhamento a 
uma estética globalizada. Os dois primeiros aspectos (caracterização do carioca e imagem da cidade) também servem para demonstrar a contribuição da imagem do Rio para o êxito da Copa, enquanto o último (homologia entre a idade e a identidade brasileira) aponta para uma projeção do Brasil no cenário global, revelando, com isso, uma demonstração da contribuição da Copa para o Rio e o País. De forma oposta, essas funções remetem à particularidade da cidade e à sua adequação global, respectivamente.

\section{Considerações finais}

O resultado da pesquisa, por meio da formação discursiva identificada, diz respeito ao entendimento de como o Rio de Janeiro se encontra em um ponto de articulação entre sua inserção numa lógica econômico-cultural globalizada e a busca de valorização de suas qualidades naturais, humanas e culturais. Tais aspectos, por sua vez, são extrapolados para a forma de o Rio de Janeiro ser visto como capaz de representar a própria imagem do Brasil nessa dupla finalidade.

Retornando à noção de estética da existência como lente para uma reflexão teórica sobre esses achados, um primeiro aspecto que se faz relevante discutirmos diz respeito à própria maneira como os dois fundamentos da formação enunciativa identificada são estilizados. As regras que a sustentam remetem a saberes acerca do que seja o global e o local que mais parecem imagens consagradas do que noções problematizadas: de um lado, o global como lócus desterritorializado do mundo moderno e do progresso humano; de outro, o local como demarcador de um modo de vida tradicional e estranho ao mundo desenvolvido. Assim, a maneira como evidenciamos essas concepções na investigação apontam para um regime de verdade, que, por sua vez, parecem findar por indicar a maneira como elas são significadas, justamente por assim serem esperadas.

Diante desse regime, a imagem do carioca que identificamos nos achados poderia ser entendida como aquela do olhar do outro, de fora, mas o que verificamos é justamente a própria versão de si como algo adequado para si e para o outro (estrangeiro). Tal aspecto poderia ser analisado como subserviência, mas aqui é interpretado como resistência. A concepção de que seja possível adequar-se ao global sem perder de vista o local pitoresco aponta para um entendimento de que a busca pela inserção no cenário globalizante da cultura ocidental não se faz sem que se pretenda preservar particularidades. $O$ sujeito que acata o entendimento de que um espaço social globalizado é querido é o mesmo que não está disposto a abrir mão de preservar características que possibilitam sua subjetividade singular.

É curioso refletirmos, no entanto, sobre como essa dinâmica inverte-se quando tal singularidade pretende-se extensível para o Brasil como um todo. A “carioquice” é apresentada como uma prática de existência adequada à inserção do País em um mundo desenvolvido. Assim, é possível tratar-se de outro 
COPA DO MUNDO 2014: UM BRASIL CARIOCA

PARA GRINGO VER
André Luiz Maranhão de Souza Leão Bruno Rafael Torres Ferreira Thiago Ianatoni Camargo Bruno Melo Moura

"outro": o brasileiro de forma geral. Nesse entendimento, a notoriedade internacional do Rio de Janeiro e sua associação como imagem do Brasil e da brasilidade seriam, pois, uma estética propícia à inserção do País em um cenário global. A Copa do Mundo, por sua vez, mostra-se como uma oportunidade fundamental dessa estratégia: por um lado, apresenta-se como emblemática do mundo desenvolvido; por outro, remete a um dos pontos dessa singularidade, tendo o Brasil como país do futebol e o Maracanã como seu espaço por excelência.

Assim, ao denominarmos a formação discursiva como "um Brasil carioca para gringo ver" tivemos em vista evidenciar uma estética institucionalizada e compreendida como passível de ser reconhecida mundialmente. A "carioquice" evidencia-se, na investigação, como uma subjetividade capaz de sustentar um modo de vida particular (i.e., brasileiro) e, ao mesmo tempo, fazer-se legítima perante o olhar do outro (estrangeiro).

É evidente que uma limitação investigativa diz respeito a não termos acessado outras cidades brasileiras que serviram como sede do mundial. Seria de esperar-se a identificação de estilizações particulares, inclusive, potencialmente, resistentes à noção do Rio de Janeiro e da "carioquice" como lócus e modo de vida emblemáticos do Brasil e da brasilidade. Todavia isso é tanto um escopo de pesquisa quanto uma oportunidade de investigação futura.

\section{Agradecimentos}

O presente trabalho foi realizado por meio de fomento do Conselho Nacional de Desenvolvimento Científico e Tecnológico (CNPq).

\section{Referências}

ARNOULD, E. J.; THOMPSON, C. J. Introduction: Consumer Culture Theory: ten years gone (and beyond). Consumer Culture Theory, vol. 17, n. ${ }^{\circ}$ 1, p. 1-21, 2015.

BECKETT, A. Governing the consumer: technologies of consumption. Consumption Markets \& Culture, vol. 15, n. ${ }^{\circ}$ 1, p. 1-18, 2012.

BRYCE, D.; MACLAREN, A. C.; O'GORMAN, K. D. Historicising consumption: orientalist expectations of the Middle East. Consumption Markets \& Culture, vol. 16, n. ${ }^{\circ}$ 1, p. 45-64, 2013.

CANNIFORD, R.; KARABABA, E. Partly primitive: discursive constructions of the domestic surfer.

Consumption Markets \& Culture, vol. 16, n. ${ }^{\circ}$ 2, p. 119-144, 2013. 
COLL, S. Consumption as biopower: governing bodies with loyalty cards. Journal of Consumer Culture, vol. 13, n. ${ }^{\circ}$ 3, p. 201-220, 2013.

CUNHA, S. K. da; CUNHA, J. C. Competitividade e sustentabilidade de um cluster de turismo: uma proposta de modelo sistêmico de medida do impacto do turismo no desenvolvimento local. RAC, vol. 9, n. ${ }^{\circ}$ 2, 63-79, 2005.

DERMODY, M. B.; TAYLOR, S. L.; LOMANNO, M. V. The impact of NFL Games on Lodging Industry Revenue. Journal of Travel \& Tourism Marketing, vol. 14, n. ${ }^{\circ}$ 1, p. 21-36, 2003.

FLICK, U. Introdução à pesquisa qualitativa. 3. ed. Porto Alegre: Bookman/Artmed, 2009.

FOUCAULT, M. A arqueologia do saber. 8. ed. Rio de Janeiro: Forense Universitária, 2014a.

. A ética do cuidado de si como prática da liberdade. In: MOTTA, M. B. (Org.). Ditos \& escritos, vol. 5: Ética, sexualidade, política. 2. ed. Rio de Janeiro: Forense Universitária, 2010c, p. 264287.

A ordem do discurso: aula inaugural no Collège de France pronunciada em 2 de dezembro de 1970. 21. ed. São Paulo: Edições Loyola, 2011.

. Do governo dos vivos: curso do Collège de France (1979-1980). São Paulo: Martins Fontes, 2014b.

. Em defesa da sociedade: curso do Collège de France (1975-1976). 2. ed. São Paulo: Martins Fontes, 2010b.

História da sexualidade, vol. 1: A vontade de saber. Rio de Janeiro: Edições Graal, 1988.

História da sexualidade, vol. 2: O uso dos prazeres. Rio de Janeiro: Edições Graal, 1984.

. O sujeito e o poder. In: DREYFUS, H.; RABINOW, P. Michel Foucault: uma trajetória filosófica para além do estruturalismo e da hermenêutica. 2. ed. Rio de Janeiro: Forense Universitária, p. 273-295, 2010a.

. Subjetividade e verdade: curso no Collège de France (1980-1981). São Paulo: Martins Fontes, 2016.

Uma estética da existência. In: MOTTA, M. B. (Org.). Ditos \& escritos, vol. 5: Ética, sexualidade, política. 2. ed. Rio de Janeiro: Forense Universitária, 2010d, p. 288-293.

GOULDING, C.; SAREN, M. Performing identity: an analysis of gender expressions at the Whitby Goth Festival. Consumption Markets \& Culture, vol. 12, n. ${ }^{\circ}$ 1, p. 27-46, 2009.

GOVERNO DO RIO DE JANEIRO. Rio sediará o centro de imprensa da Copa do Mundo 2014. Site. Publicado em 27 maio 2011. Disponível em: http://www.rj.gov.br/web/imprensa/exibeconteudo?article-id=477528. Acesso em: 4 jul. 2016. 
HANNA, P. A break from 'reality': an investigation into the 'experiments with subjectivity'on offer within the promotion of sustainable tourism in the UK. Journal of Consumer Culture, vol. 13, n. ${ }^{\circ}$ 3, p. 366-386, 2013.

JOHNSON, G. D.; THOMAS, K. D.; GRIER, S. A. When the burger becomes halal: a critical discourse analysis of privilege and marketplace inclusion. Consumption Markets \& Culture, vol. 20, n. ${ }^{\circ}$ 6, p. 497-522, 2017.

LEÃO, A. L. M. S.; FERREIRA, B. R. T.; CAMARGO, T. I.; SOUZA. I. L. La Copa del Mundo Fifa 2014: análisis de los discursos en torno a la promesa de desarrollo turístico del Nordeste Brasileño. Estudios y Perspectivas en Turismo, vol. 26, p. 370-393, 2017.

LINCOLN, Y. S.; LYNHAM, S. A.; GUBA E. G. Paradigmatic controversies, contradictions, and emerging confluences, revisited. In: DENZIN, N. K.; LINCOLN, Y. S. The sage handbook of qualitative research. 5. ed. Thousand Oaks: Sage Publications, 2018, p.108-150.

MENDONÇA, A. V. Rio recebeu 886 mil turistas durante a Copa do Mundo, diz Riotur. Site. Publicado em 17 jul. 2014. Disponível em: http://g1.globo.com/rio-de-janeiro/noticia/2014-/07/rio-recebeu886-mil-turistas-durante-copa-do-mundo-diz-riotur.html. Acesso em: 1 jul. 2016.

MIKKONEN, I.; MOISANDER, J.; FIRAT, A. F. Cynical identity projects as consumer resistance: the Scrooge as a social critic?. Consumption Markets \& Culture, vol. 14, n. ${ }^{\circ}$ 1, p. 99-116, 2011.

PAIVA JR, F. G.; LEÃO, A. L. M. S.; MELLO, S. C. Validade e confiabilidade na pesquisa qualitativa em Administração. Revista de Ciências da Administração, vol. 13, n. ${ }^{\circ}$ 31, p. 190-209, 2011.

PERFETTO, R.; DHOLAKIA, N. Exploring the cultural contradictions of medical tourism. Consumption, Markets and Culture, vol. 13, n. ${ }^{\circ}$ 4, p. 399-417, 2010.

PORTAL BRASIL. Eventos internacionais no Brasil crescem em 400\%. Site. Publicado em 23 dez. 2017. Disponível em: http://www.brasil.gov.br/noticias/turismo/2016/08/eventosinternacionais-no-brasil-crescem-em-400. Acesso em: 16 mar. 2018.

REVISTA EXAME. Ocupação da rede hoteleira durante a Copa atinge expectativa. Site. Publicado em 28 maio 2014. Disponível em: http://exame.abril.com.br/economia/noticias/-ocupacao-da-redehoteleira-durante-a-copa-atinge-expectativa. Acesso em: 4 jul. 2016.

SOUZA, D. A.; GIL, A. C. A importância da identidade regional na configuração de clusters turísticos. Revista Turismo em Análise, vol. 26, n. ${ }^{\circ}$ 2, p. 475-492, 2015.

SOUZA-LEÃO, A. L. M. de; COSTA, F. Z. N. Assemblaged by desire: potterheads' productive consumption. Revista de Administracão de Empresas, vol. 58, n. ${ }^{\circ}$ 1, p. 74-86, 2018.

SOUZA-LEÃO, A. de; MOURA, B. Temos que pegar todos!: discursos identitários sobre o consumo de Pokemon GO no Brasil. Revista Brasileira de Marketing, vol. 17, n. ${ }^{\circ}$ 6, p. 895-913, 2018.

VOASE, R. Individualism and the 'new tourism': a perspective on emulation, personal control and choice. International Journal of Consumer Studies, vol. 31, n. ${ }^{\circ}$ 5, p. 541-547, 2007. 
WEISKOPF, R. Deconstructing "The Iron Cage": towards an aesthetic of folding. Consumption Markets \& Culture, vol. 5, n. ${ }^{\circ}$ 1, p. 79-96, 2002.

YNGFALK, C. Bio-politicizing consumption: neo-liberal consumerism and disembodiment in the food marketplace. Consumption Markets \& Culture, vol. 19, n. ${ }^{\circ}$ 3, p. 275-295, 2016.

ZAJC, M. Social media, prosumption, and dispositives: new mechanisms of the construction of subjectivity. Journal of Consumer Culture, vol. 15, n. ${ }^{0}$ 1, p. 28-47, 2015.

ZWICK, D.; DENEGRI KNOTT, J. Manufacturing customers: the database as new means of production. Journal of Consumer Culture, vol. 9, n. ${ }^{\circ}$ 2, p. 221-247, 2009. 